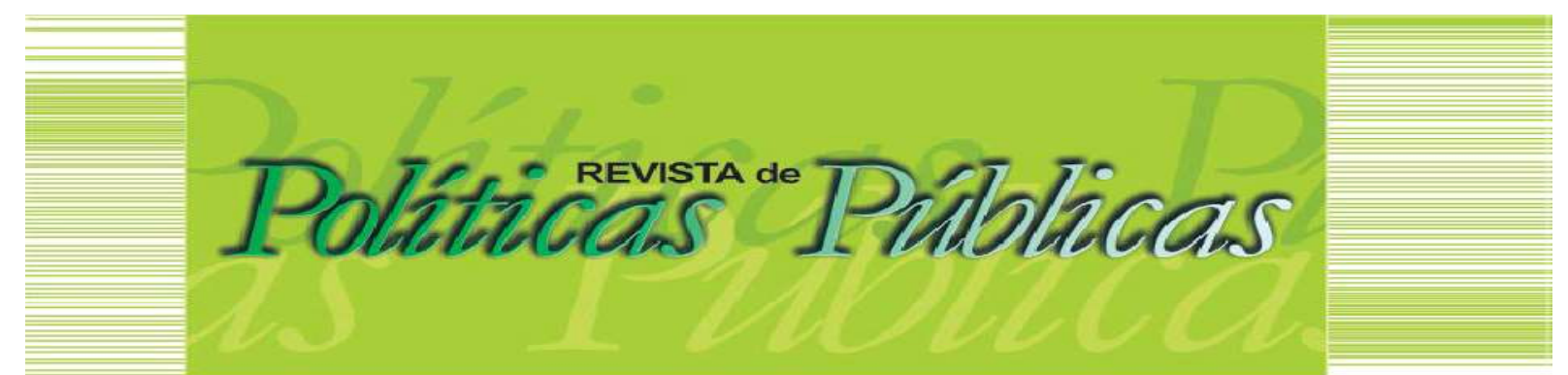

\title{
PADRÃO DE ESPECIALIZAÇÃO DO COMÉRCIO INTERNACIONAL DO MARANHÃO (1999-2016)
}

\author{
Laís Viera Trevisan 1 \\ Alison Geovani Schwingel Franck² \\ Rodrigo Abbade da Silva ${ }^{3}$ \\ Daniel Arruda Coronel ${ }^{4}$
}

Resumo: Este estudo buscou avaliar o padrão de especialização do comércio internacional do Estado do Maranhão, identificando os setores produtivos mais dinâmicos, no período entre 1999 e 2016. Nesse sentido, foram calculados os indicadores de Vantagem Comparativa Revelada Simétrica (IVCRS), de Comércio Intraindústria (CII) e de Concentração Setorial das Exportações (ICS). Os resultados dos cálculos do IVCRS e do Cll apontam que o estado possui dois setores competitivos no mercado internacional, os quais são metais comuns e químicos. Além daqueles indicadores, o ICS indicou que o Maranhão tem uma pauta de exportações concentrada em poucos setores, sendo pouco diversificada.

Palavras-chave: Exportações. Vantagem comparativa. Maranhão.

\section{THE SPECIALIZATION PATTERN OF INTERNATIONAL TRADE OF MARANHÃO (1999-2016)}

Abstract: This study aimed to evaluate the specialization pattern in international trade in the state of Maranhão, identifying the most dynamic productive sectors in the period between 1999 and 2016. In this sense, the Revealed Symmetric Comparative Advantage (IRSCA) indicator was calculated, as well as the Intra-industry trade index (IIT), the Industry Concentration of Exports (ICS), and the Import Coverage Ratio (IC). The results of the calculations of the RSCA and the IIT indicate that the state has two competitive sectors in the international market: common metals and chemicals. In addition to these indicators, the ICS indicated that Maranhão has an export basket concentrated in a few sectors, with little diversification, and the IC pointed out that the footwear and leather, textiles and metals are the sectors that most exceed imports in relation to the exported value.

Keywords: Exports. Comparative advantages. Maranhão

Artigo recebido em: 12/10/2018 Aprovado em: 12/09/2019 DOI: http://dx.doi.org/10.18764/2178-2865.v23n2p844-862.

\footnotetext{
1 Administradora. Mestranda do Programa de Pós-Graduação em Gestão de Organizações Públicas (PPGOP) da Universidade Federal de Santa Maria (UFSM). Assistente em Administração na Pró-Reitoria de Administração da UFSM. Email: laisvtrevisan@gmail.com

${ }^{2}$ Contador. Mestrando do Programa de Pós-Graduação em Administração (PPGA) da Universidade Federal de Santa Maria (UFSM). E-mail: alischfranck@hotmail.com

3 Economista. Doutorando do Programa de Pós-Graduação em Administração (PPGA) da Universidade Federal de Santa Catarina (UFSC). E-mail:abbaders@gmail.com

${ }^{4}$ Economista. Administrador. Mestre em Agronegócios pela Universidade Federal do Rio Grande do Sul (UFRGS). Doutor em Economia Aplicada pela Universidade Federal de Viçosa (UFV). Professor Associado do Departamento de Economia e Relações Internacionais, com atuação como Docente Permanente nos Programas de Pós-Graduação (Stricto sensu) em Gestão de Organizações Públicas, de Agronegócios e de Economia e Desenvolvimento, da Universidade Federal de Santa Maria (UFSM). E-mail: daniel.coronel@uol.com.br
} 


\section{INTRODUÇÃO}

Na década de 1990 ocorreu no Brasil um aprofundamento do processo de liberalização econômica, proporcionando a entrada dos produtos brasileiros no mercado internacional, bem como a inserção de diversos produtos estrangeiros no país. Com as medidas tomadas na época, esperava-se uma maior exposição ao comércio internacional e um aumento da competitividade das empresas nacionais.

De acordo com Rossi Júnior e Ferreira (1999), a abertura comercial permitiu maior especialização do país nos setores em que sua vantagem competitiva é maior, aumentando sua produtividade média e marginal.

As relações comerciais entre as nações são fontes de estudo de diversas teorias. A primeira delas foi a Teoria da Vantagem Absoluta, de Adam Smith (1984), a qual, conforme Coutinho et al. (2005), afirmam que cada país deve se concentrar na produção dos bens que the oferecem vantagem absoluta. David Ricardo (1982) desenvolveu a Teoria das Vantagens Comparativas, enfatizando que as vantagens comparativas são provenientes de um único fator: as diferenças existentes entre as nações com relação à produtividade do trabalho (HIDALGO; MATA, 2004). Em 1933 surgiu a Teoria das Proporções dos Fatores, criada pelos economistas suecos Eli Heckscher e Bertil Ohlin, a qual evidenciou as diferenças internacionais nas dotações de fatores. Segundo essa teoria, um país exporta mercadorias intensivas no fator relativamente abundante e importa mercadorias intensivas no fator escasso (HIDALGO, 1998).

Dentro dessa discussão, compreende-se a significância do tema para o desenvolvimento de estratégias de comércio internacional das nações e evidencia-se a importância de estudar a pauta exportadora dos estados brasileiros. Neste artigo, especificamente, será abordado o padrão de exportações do Maranhão, bem como os impactos da sua abertura comercial.

Nesse contexto, este estudo visa analisar o padrão de especialização das exportações do Maranhão, no período de 1999 a 2016, identificando os setores produtivos mais dinâmicos do estado e compreendendo a composição da sua pauta exportadora. Para alcançar tais objetivos, foram utilizados alguns índices de comércio internacional. São eles: indicador de Vantagem Comparativa Revelada Simétrica (IVCRS), Comércio Intraindústria (CII) e Concentração Setorial das Exportações (ICS).

Assim, este artigo está estruturado da seguinte forma, além desta introdução: na seção 2 , é apresentada a estrutura das exportações do Maranhão; posteriormente, na seção 3, apresenta-se a descrição dos procedimentos metodológicos; na seção 4, são analisados os resultados obtidos e, por fim, na seção 5 , são pontuadas as considerações finais do trabalho. 


\section{A ESTRUTURA DAS EXPORTAÇÕES DO MARANHÃO}

De acordo com o Ministério do Desenvolvimento, Indústria e Comércio Exterior (MDIC, 2017a), em 2016, as exportações do Maranhão totalizaram US\$2.209.829.779, ocupando a $13^{\text {a }}$ posição no ranking dos estados brasileiros, com uma participação de 1,23\% nas exportações da nação e de $17,25 \%$ nas da região Nordeste. Já em 1999, o valor era de US\$ 662.962 .367 (11 ${ }^{a}$ posição nacional), 1,42\% de participação nas exportações do país e 19,76\% nas nordestinas. De 1999 a 2016 , as exportações do Maranhão cresceram 232\%, enquanto as do Brasil, $284 \%$.

Em relação às importações do Maranhão, o valor total em 2016 foi de US\$ 2.101.599.489 (14a posição nacional), com uma participação de 11,98\% nas importações nordestinas e de $1,53 \%$ nas do país. Em 1999, o valor era de US $\$ 366.930 .370$, e o estado figurava na $13^{\text {a }}$ posição nacional. De 1999 a 2016, as importações do estado cresceram 472,5\%, já as do Brasil, 179\%. A partir desses dados, nota-se que, ao longo do período analisado, as exportações do estado cresceram menos em relação ao âmbito nacional, enquanto as importações cresceram mais.

A Figura 1 mostra as exportações do Maranhão de acordo com 0 fator agregado. Observa-se que, em 1999, as exportações do estado concentravam-se em produtos semimanufaturados, com cerca de $80 \%$ de representatividade. Entretanto, ao longo dos anos, houve mudanças nesse cenário. Em 2010, os produtos básicos eram responsáveis por $66,6 \%$ das exportações. Entretanto, os manufaturados começaram a aumentar sua proporção, chegando a 42,6\% em 2016, seguidos pelos semimanufaturados e básicos.

Figura 1 - Exportações (X) do Maranhão segundo fator agregado (em milhões US\$ FOB)

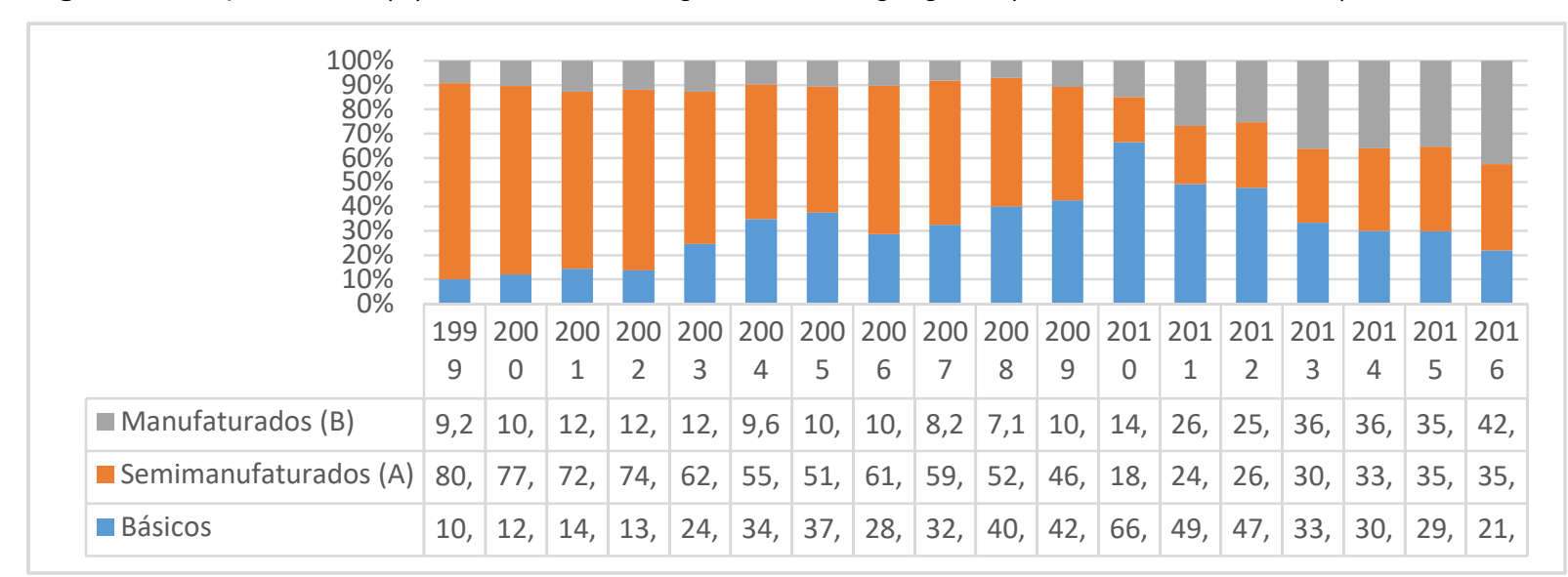

Fonte: Elaboração própria a partir dos dados MDIC/SECEX (2017b)

No que tange às importações (Figura 2), houve poucas alterações ao longo do período analisado, demonstrando que o Maranhão concentrou suas demandas em produtos manufaturados, importando uma pequena proporção de produtos básicos e semimanufaturados. Destaca-se que 0 
gasóleo (óleo diesel) é o principal produto importado pelo estado, representando aproximadamente 29\% das importações no ano de 2016 (MDIC, 2017a).

Figura 2 - Importações (M) do Maranhão segundo fator agregado (em milhões US\$ FOB) - Maranhão

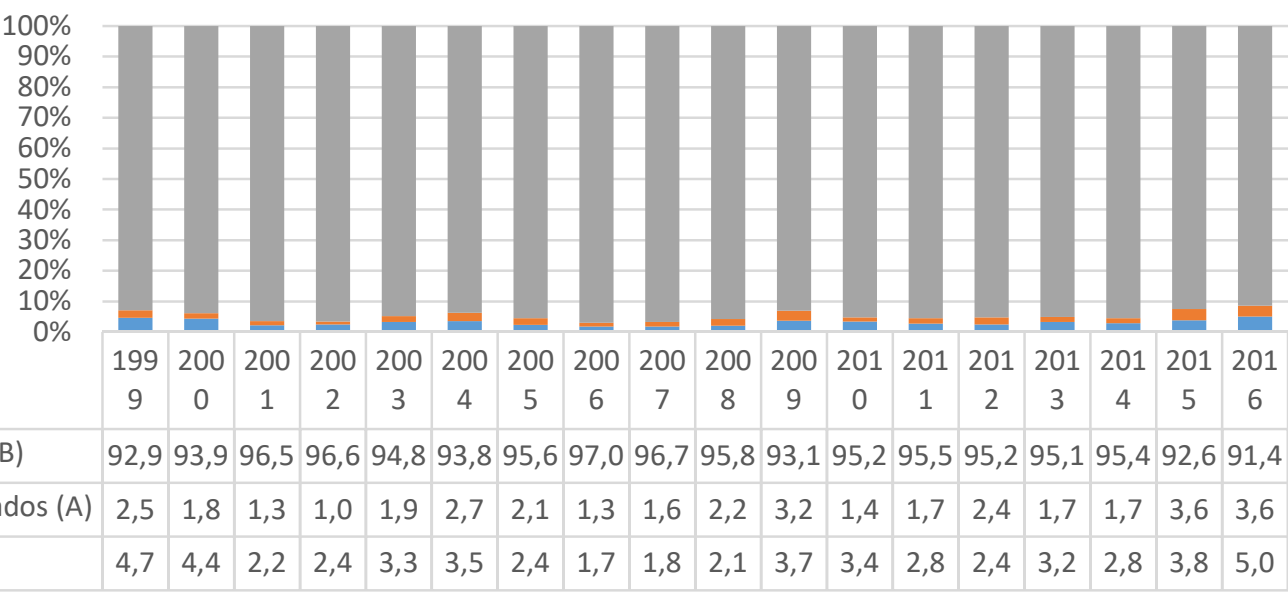

Fonte: Elaboração própria a partir dos dados MDIC/SECEX (2017b)

Considerando-se a relevância das exportações no papel de especialização comercial, são analisados os quatro principais destinos das exportações do Maranhão entre 1999 e 2016 (Tabela 1).

Tabela 1 - Destino das exportações e sua participação no total exportado por MA - 1999 e 2016

\begin{tabular}{|c|c|c|c|c|c|c|c|}
\hline Posição & Países de destino & $\begin{array}{l}\text { Exp. em } 2016 \\
\text { (milhões US\$ } \\
\text { FOB) }\end{array}$ & $\begin{array}{c}\text { Part. \% } \\
\text { em } \\
2016\end{array}$ & Posição & Países de destino & $\begin{array}{c}\text { Exp. em } 1999 \\
\text { (milhões US\$ } \\
\text { FOB) }\end{array}$ & $\begin{array}{c}\text { Part. } \\
\% \\
\text { em } \\
1999\end{array}$ \\
\hline $1^{\circ}$ & Canada & 378,59126 & 17,1 & $1^{\circ}$ & Países Baixos (Holanda) & 152,53657 & 23,0 \\
\hline $2^{\circ}$ & Estados Unidos & 362,09813 & 16,4 & $2^{\circ}$ & Estados Unidos & 146,24122 & 22,1 \\
\hline $3^{\circ}$ & China & 235,74489 & 10,7 & $3^{\circ}$ & Belgica (luxemburgo) & 103,56887 & 15,6 \\
\hline $4^{\circ}$ & Países Baixos (Holanda) & 201,30357 & 9,1 & $6^{\circ}$ & China & 30,644682 & 4,6 \\
\hline \multirow[t]{3}{*}{$<30^{\circ}$} & Bélgica (luxemburgo) & 7,350716 & 0,3 & $30^{\circ}$ & Canada & 0,002907 & 0,0 \\
\hline & Demais Países & 1024,7 & 46,4 & & Demais Países & 230,0 & 34,7 \\
\hline & Total & 2209,8298 & 100,0 & & Total & 662,96237 & 100,0 \\
\hline
\end{tabular}

Fonte: Elaboração própria a partir dos dados MDIC/SECEX (2017b).

Entre o período de 1999 e 2016 houve algumas mudanças no cenário dos principais destinos das exportações maranhenses. Em 1999, os Países Baixos (Holanda) ocupavam o primeiro lugar no ranking, com 23\% das exportações, já em 2016, passou para quarto lugar, com 9,1\% de participação. Os Estados Unidos mantiveram a segunda posição, apenas diminuindo sua representatividade de 22,1\% para 16,4\%. A Bélgica, que ocupava o terceiro lugar, em 2016 passou para a trigésima. A China representava 4,6\% em 1999, ocupando a sexta posição, e, em 2016, 


\section{PADRÃO DE ESPECIALIZAÇÃO DO COMÉRCIO INTERNACIONAL DO MARANHÃO (1999-2016)}

aumentou sua proporção para 10,7\%, passando para terceiro lugar. O Canadá, que em 1999 ocupava a trigésima posição, em 2016 foi o principal destino das exportações maranhenses, representando $17,1 \%$ das vendas do estado. Assim, observa-se que, em 2016, 53,3\% das vendas do Maranhão concentraram-se em quatro países: Canadá, Estados Unidos, China e Países Baixos (Holanda).

Em relação à estrutura das exportações do Maranhão segundo os grupos de produtos (Tabela 2), os cinco setores que apresentaram as maiores taxas de crescimento das exportações foram alimentos/fumo/bebidas, minerais, químicos, papel e têxtil. No entanto, alguns setores apresentaram crescimento negativo (decrescimento): madeira, minerais não metais/metais preciosos, metais comuns, ótica/instrumentos.

Segundo o Escritório Técnico de Estudos Econômicos do Nordeste (ETENE, 2017), no período de janeiro a abril de 2017, o Maranhão ocupou o segundo lugar, entre os estados do Nordeste, em volumes de vendas para o mercado internacional, com 17,2\% de participação nas vendas nordestinas. O estudo verificou uma mudança no perfil do comércio exterior em diferentes unidades federativas, como nas vendas de alumina, papel e celulose, além da soja no Maranhão. A alumina foi 0 produto mais vendido pelo estado, que respondeu com quase metade do volume exportado $(47,5 \%)$, seguida pela pasta química de madeira $(22,7 \%)$ e soja $(17,8 \%)$, enquanto álcool $(29,3 \%)$, óleo diesel $(26,5 \%)$ e gasolina $(22,0 \%)$ foram os produtos mais importados. Apesar do bom desempenho, o saldo da balança comercial maranhense é negativo em U\$ 153,3 milhões, resultado de U\$ 830,9 milhões em exportações e U\$ 984,2 milhões em importações.

De acordo com o Instituto Maranhense de Estudos Socioeconômicos e Cartográficos (IMESC, 2017), na pauta de exportações do Maranhão, houve um crescimento de US\$121,7 milhões no acumulado de janeiro a abril de 2017 em relação ao mesmo período de 2016, e isso se deve principalmente a dois fatores: a melhora dos preços internacionais das commodities metálicas, que elevou o valor das exportações de alumina calcinada em mais $45,6 \%$ e de ferro gusa em mais $35,7 \%$, mesmo com redução na quantidade exportada destes produtos; e a retomada da produção agrícola, sobretudo no complexo de soja, em virtude da normalização das chuvas na região produtora, possibilitando a recuperação da produção graneleira. Entretanto, alguns produtos apresentaram redução, com destaque para o milho (-86,7\%) e para o algodão debulhado $(-42,3 \%)$, em função de que tiveram as segundas safras antecipadas devido ao clima do ano passado, e assim, divergindo do ano corrente em que o produto deve ser colhido entre as safras da soja, devendo ser exportado mais tarde. Os resultados negativos também foram registrados nas exportações de pasta de celulose, que registraram redução de $6,1 \%$ na quantidade, devido a paralisações programadas para manutenção, e de $20,6 \%$ no valor, em decorrência da queda dos preços internacionais. 
Tabela 2 - Estrutura das exportações do Maranhão segundo grupos de produtos/setores em (\%)

\begin{tabular}{|c|c|c|c|c|c|c|c|c|c|c|c|c|c|c|c|c|c|c|c|}
\hline Setoreslperíodos & 1999 & 2000 & 2001 & 2002 & 2003 & 2004 & 2005 & 2006 & 2007 & 2008 & 2009 & 2010 & 2011 & 2012 & 2013 & 2014 & 2015 & 2016 & $\begin{array}{c}\text { Taxa } \\
\text { de cresc. } \\
1999 \text { a } 2016\end{array}$ \\
\hline Alimentos/fumo/bebidas & 10,2 & 12,1 & 14,4 & 13,5 & 17,4 & 15,6 & 15,2 & 13,7 & 12,5 & 16,4 & 34,1 & 14,5 & 20,2 & 28,5 & 31,7 & 28,9 & 28,5 & 19,7 & 544,8 \\
\hline Minerais & 0,0 & 0,0 & 0,0 & 0,2 & 7,2 & 19,1 & 22,4 & 14,9 & 19,9 & 23,5 & 7,6 & 51,6 & 27,9 & 18,0 & 0,3 & 0,0 & 0,0 & 1,5 & 32096136900,0 \\
\hline Químicos & 8,8 & 9,6 & 11,7 & 10,4 & 10,6 & 8,1 & 9,1 & 9,4 & 7,6 & 6,6 & 10,2 & 14,9 & 26,5 & 25,3 & 35,9 & 36,1 & 35,3 & 41,0 & 1447,5 \\
\hline Plástico/borracha & 0,0 & 0,0 & 0,0 & 0,0 & 0,0 & 0,0 & 0,0 & 0,0 & 0,0 & 0,0 & 0,0 & 0,0 & 0,0 & 0,0 & 0,0 & 0,0 & 0,0 & 0,0 & 60900,0 \\
\hline Calçados/couro & 0,2 & 0,2 & 0,1 & 0,3 & 0,1 & 0,0 & 0,1 & 0,2 & 0,2 & 0,0 & 0,0 & 0,1 & 0,4 & 0,1 & 0,1 & 0,1 & 0,1 & 0,3 & 301,7 \\
\hline Madeira & 0,4 & 0,5 & 1,1 & 1,3 & 1,7 & 1,0 & 0,8 & 0,7 & 0,6 & 0,3 & 0,1 & 0,0 & 0,0 & 0,0 & 0,0 & 0,0 & 0,0 & 0,0 & $-73,0$ \\
\hline Papel & 0,0 & 0,0 & 0,0 & 0,1 & 0,1 & 0,3 & 0,3 & 0,0 & 0,0 & 0,0 & 0,0 & 0,0 & 0,0 & 0,0 & 0,0 & 16,6 & 23,9 & 26,4 & 581356797900,0 \\
\hline Têxtil & 0,0 & 0,0 & 0,0 & 0,0 & 0,1 & 0,2 & 0,1 & 0,2 & 0,2 & 0,3 & 1,4 & 0,6 & 1,2 & 1,4 & 1,5 & 1,1 & 1,3 & 2,2 & 2117605,4 \\
\hline Min. N.-met/met. Preciosos & 0,0 & 0,0 & 0,0 & 0,0 & 0,0 & 0,0 & 0,0 & 0,0 & 0,0 & 0,0 & 0,0 & 0,5 & 2,2 & 4,2 & 4,3 & 3,0 & 1,7 & 0,0 & $-100,0$ \\
\hline Metais comuns & 80,4 & 77,4 & 72,7 & 73,8 & 62,4 & 55,4 & 51,8 & 60,9 & 59,1 & 52,7 & 46,7 & 17,8 & 21,4 & 22,4 & 26,0 & 14,1 & 9,3 & 8,9 & $-63,4$ \\
\hline Máquinas/equipamentos & 0,0 & 0,0 & 0,0 & 0,0 & 0,0 & 0,0 & 0,0 & 0,0 & 0,0 & 0,0 & 0,0 & 0,0 & 0,0 & 0,0 & 0,0 & 0,0 & 0,0 & 0,0 & 334663900,0 \\
\hline Material transporte & 0,0 & 0,0 & 0,0 & 0,0 & 0,0 & 0,0 & 0,0 & 0,0 & 0,0 & 0,0 & 0,0 & 0,0 & 0,0 & 0,0 & 0,0 & 0,0 & 0,0 & 0,0 & 267906900,0 \\
\hline Ótica/instrumentos & 0,0 & 0,0 & 0,0 & 0,0 & 0,0 & 0,0 & 0,0 & 0,0 & 0,0 & 0,0 & 0,0 & 0,0 & 0,0 & 0,0 & 0,0 & 0,0 & 0,0 & 0,0 & $-100,0$ \\
\hline Outros & 0,0 & 0,2 & 0,0 & 0,3 & 0,4 & 0,4 & 0,3 & 0,0 & 0,0 & 0,0 & 0,0 & 0,0 & 0,2 & 0,1 & 0,2 & 0,0 & 0,0 & 0,0 & $-100,0$ \\
\hline Total & 100,0 & 100,0 & 100,0 & 100,0 & 100,0 & 100,0 & 100,0 & 100,0 & 100,0 & 100,0 & 100,0 & 100,0 & 100,0 & 100,0 & 100,0 & 100,0 & 100,0 & 100,0 & 232,0 \\
\hline
\end{tabular}

Fonte: Elaboração própria a partir dos dados MDIC/SECEX (2017b) 


\section{METODOLOGIA}

Nesta seção, identificam-se os quatro indicadores utilizados para o desenvolvimento deste estudo: Vantagem Comparativa Revelada Simétrica (IVCRS), de Comércio Intraindústria (CII), de Concentração Setorial das Exportações (ICS), a partir de dados da Secretaria de Comércio Exterior SECEX, os quais objetivam demonstrar os setores do Maranhão com vantagens comparativas no comércio exterior, ou seja, os setores mais especializados no comércio internacional do estado do Maranhão.

O indicador de Vantagem Comparativa Revelada Simétrica (IVCRS) é formalmente definido pela Expressão (1). Este indicador revela a relação entre participação de mercado do setor e a participação da região (estado) no total das exportações do país, fornecendo uma medida da estrutura relativa das exportações de uma região (estado). O IVCRS varia de forma linear entre -1 e 1.0 país/região que tiver resultado entre 0 e 1, terá vantagem comparativa no produto analisado. Se 0 IVCRS for igual a zero, terá a competitividade média dos demais exportadores e, se variar entre -1 e 0 , terá desvantagem comparativa (SILVA et al., 2015).

$$
\operatorname{IVCRS~}_{i k}=\frac{\mathrm{x}_{i j} / \mathrm{x}_{i z}}{\mathrm{x}_{j} / \mathrm{x}_{z}}-1 / \frac{\mathrm{x}_{i j} / \mathrm{x}_{i z}}{\mathrm{x}_{j} / \mathrm{x}_{z}}+1
$$

Em que:

$X_{i j}$ representa valor das exportações do setor i pelo Estado j (MA);

$X_{i z}$ representa o valor das exportações do setor i da zona de referência z (Brasil);

Xj representa valor total das exportações do estado j (MA); e,

$\mathrm{X}_{\mathrm{z}}$ representa valor total das exportações da zona de referência $\mathrm{z}$ (Brasil).

Para Hidalgo (1998), quando uma região exporta um grande volume de um determinado produto em relação ao que é exportado desse mesmo produto pelo país, ela possui vantagem comparativa na produção desse bem.

O segundo é o Índice de Comércio Intraindústria (CII), o qual visa caracterizar o comércio do estado do Maranhão. Este índice consiste na utilização da exportação e importação simultânea de produtos do mesmo setor. Com o avanço e difusão dos processos tecnológicos entre os países, mudam-se a configuração do comércio internacional e o peso das vantagens comparativas (abundância de recursos). Apresenta-se como destaque o crescimento do comércio intraindústria. 
Assim, diferentemente do comércio interindustrial, o comércio intraindústria é explicado pelas economias de escala e pela diferenciação do produto (SILVA et al., 2016)

$\mathrm{O}$ indicador setorial do comércio intraindustrial (CII) foi desenvolvido por Grubel e Lloyd (1975), e pode ser apresentado conforme a Equação 2:

$$
C I I=1-\frac{\sum_{i}\left|X_{i}-M_{i}\right|}{\sum_{i}\left(X_{i}+M_{i}\right)}
$$

Em que:

$X_{i}$ representa as exportações do produto i;

$\mathrm{M}_{\mathrm{i}}$ representa as importações do produto i.

Quando o indicador Cll se aproximar de zero, pode-se concluir que há comércio interindustrial; neste caso, o comércio é explicado pelas vantagens comparativas, ou seja, observa-se a presença de comércio entre produtos de diferentes setores do Maranhão com os países parceiros. Esse evento pode ser observado ao constatar ocorrência de apenas importação ou apenas exportação do setor i (ou produto i). Por outro lado, quando $\mathrm{Cll}$ for maior que $0,5(\mathrm{C} \|>0,5)$, o comércio é caracterizado como sendo intraindustrial.

Assim, o padrão de comércio intraindustrial reflete uma pauta exportadora que, por sua vez, sucede uma estrutura produtiva dinamizada em progresso tecnológico e em economias de escala (ampliação de mercados). Todavia, a configuração interindustrial reflete o ordenamento entre os setores produtivos, baseado no uso da dotação de fatores e sob concorrência perfeita. Esse arranjo explicativo das trocas comerciais pode indicar se determinado participante do comércio internacional alcançou ganhos de competitividade. Ressalta-se que, em meio à profusão de conceitos que foram dados a esse termo, entende-se, neste artigo, diante dos alcances e das limitações dos índices utilizados, que alcançar competitividade internacional significa atingir os maiores níveis de vantagem comparativa revelada e o padrão de inserção intraindustrial.

O terceiro indicador é o índice de Concentração Setorial das Exportações (ICS), também conhecido como coeficiente Gini-Hirchman, o qual quantifica a concentração das exportações de cada setor exportador i realizadas pelo estado j (Maranhão). O ICS é representado através da Equação 3:

$$
I C S_{i j}=\sqrt{\sum_{i}\left(\frac{X_{i j}}{X_{j}}\right)^{2}}
$$

Em que:

$X_{i j}$ representa as exportações do setor i pelo estado j (MA); e,

$X_{j}$ representa as exportações totais do estado $\mathrm{j}(\mathrm{MA})$. 
O ICS varia entre 0 e 1, e, quanto mais próximo a 1, mais concentradas serão as exportações em poucos setores e, por outro lado, quanto mais próximo de 0 , mais diversificada será a composição da pauta de exportações (SILVA et al., 2017)

Para alcançar o objetivo de explanar o padrão comercial do Maranhão, no período 1999 a 2016, e apresentar os setores com maior produtividade do estado, ou seja, aqueles que apresentam maior especialização e competitividade, foram utilizados indicadores baseados nos fluxos comerciais. O banco de dados para o cálculo destes indicadores encontra-se na Secretaria do Comércio Exterior (SECEX) do Ministério do Desenvolvimento, Indústria e Comércio do Brasil (MDIC, 2017b), acessível através do Sistema de Análise de Informações do Comércio Exterior (Aliceweb2)².

Os dados relativos às importações e às exportações desagregadas por setores seguem 0 padrão da literatura empírica da área, como apresentam Feistel (2008) e Maia (2005). Tais autores estabelecem capítulos, divididos em setores produtivos, e, deste modo, cada capítulo corresponde a um agrupamento de produtos. Assim, obtêm-se os valores das importações e exportações, agregandoos no padrão já utilizado por tais autores.

\section{ANÁLISE E DISCUSSÃO DOS RESULTADOS}

\section{1 Índice de Vantagem Comparativa Revelada Simétrica - IVCRS}

A Tabela 3 demonstra a evolução do índice de Vantagens Comparativas Reveladas Simétricas do Maranhão de 1999 a 2016. Dos 14 setores analisados, em dois o Estado do Maranhão apresentou vantagens comparativas (IVCRS>0) em todos os anos da série histórica. Ou seja, esses setores apresentaram especialização permanente no que se refere à competitividade e inserção maranhense no mercado internacional. Tais setores foram os de metais comuns (média de IVCRS de 0,57) e químicos (média de IVCRS de 0,44). 
PADRÃO DE ESPECIALIZAÇÃO DO COMÉRCIO INTERNACIONAL DO MARANHÃO (1999-2016)

Tabela 3 - Índice de Vantagem Comparativa Revelada Simétrica para o Maranhão

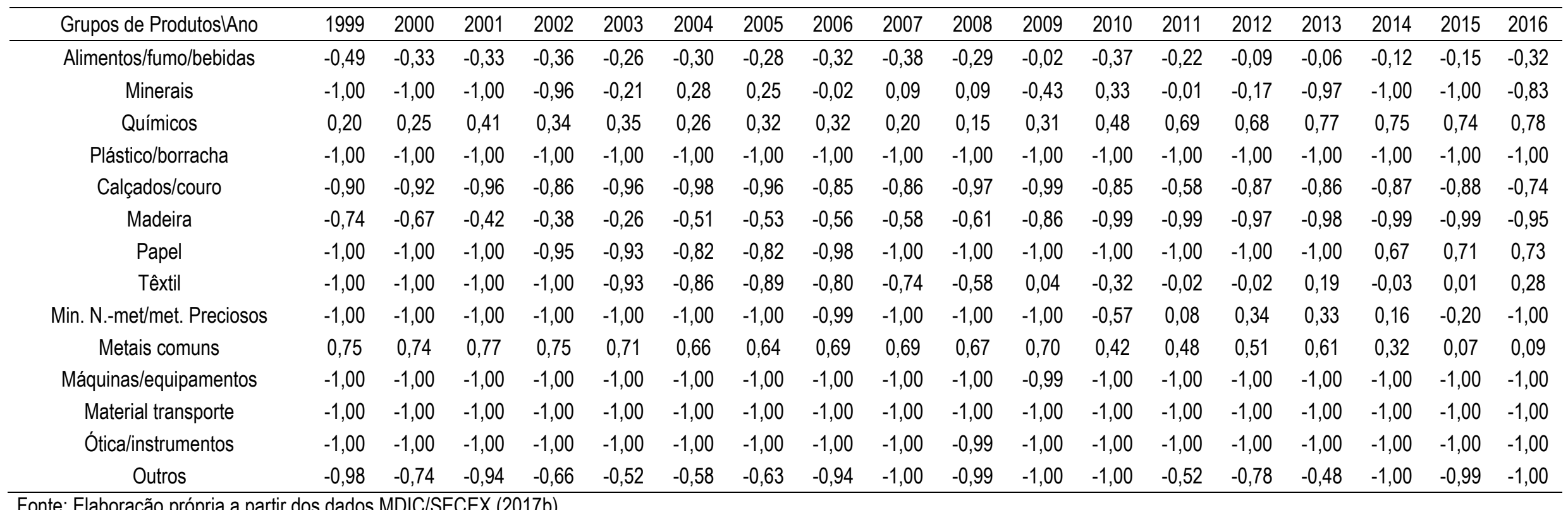




\section{PADRÃO DE ESPECIALIZAÇÃO DO COMÉRCIO INTERNACIONAL DO MARANHÃO (1999-2016)}

Segundo dados do MDIC (2017b), o desempenho do setor de metais comuns, bem como o do setor químico, está associado às exportações de ferro e aço, para o primeiro, e de corindo e óxidos e hidróxidos de alumínio, para o segundo, visto que, dentro de tais setores, tais produtos obtiveram os maiores valores de exportação. Ainda, esta percepção é corroborada com o estudo de Silva (2013), o qual avaliou o comércio exterior maranhense durante os anos 2000, e explica que, quanto às exportações do estado, merecem destaque as exportações de ferro fundido bruto não ligado, de alumínio não ligado em forma bruta, e da alumina calcinada, os quais são exportações de médiabaixa intensidade tecnológica e se apresentam como os principais produtos exportados durante 0 período.

Pode-se ainda levar em consideração em relação ao setor de metais comuns, conforme destacado por Santos (2011), Pereira (2014) e Mesquita (2011), que, apesar de o estado já ter anteriormente exportado metais, por meio da implantação do complexo Carajás, na década de 1980, ele se especializou ainda mais nas exportações de metais (abrangendo metais ferrosos e não ferrosos). Assim, o estado acabou por se especializar na exportação de produtos de baixa intensidade tecnológica, concentrando suas exportações em metais e criando vantagens comparativas para tais produtos.

Já de acordo com Oliveira e Oliveira (2017), a região oeste do Maranhão passou a apresentar expressivo crescimento econômico a partir do Programa Grande Carajás e da implantação da Ferrovia Carajás-Itaqui para o transporte de minério. Entretanto, este desenvolvimento de transportes também beneficiou o setor químico a partir do beneficiamento da celulose: em 1988, a implantação da Ferrovia Norte-Sul propiciou que, em 1992, a Celulose do Maranhão S.A. (CELMAR S.A.) conseguisse instalar uma indústria de celulose, cujo investimento foi de mais de US\$1 bilhão em plantios de eucalipto. Mais tarde, a partir de 2013, a cidade de Imperatriz, recebendo diversas concessões ofertadas pelos governos estadual e municipal (fato que proporcionou uma minimização de gastos num momento em que o setor de papel e celulose passava por uma recessão) sediou fábricas da Suzano Papel e Celulose, buscando atrair novos investimentos industriais, o que acelerou 0 processo de produção e exportação de químicos ${ }^{3}$ no estado e pode explicar a elevação do IVCRS a partir de 2013.

A partir dessas análises e sob a perspectiva das vantagens comparativas, compreende-se que o Maranhão possui poucos setores que apresentam vantagens comparativas, ou seja, pauta produtiva com pouca diversificação. Isso indica que o estado pode ser vulnerável às oscilações de variáveis externas (mudança de preços internacionais, crises etc.) e internas (estiagens etc.). 


\section{2 Índice de comércio intraindústria - CII}

Na Tabela 4, são apresentados os resultados do ClI, o qual representa o padrão comercial dentro de um mesmo setor. Dos 14 setores analisados, apenas o setor de químicos indica a existência de comércio intraindústria ao longo de todo o período analisado. Quanto aos outros setores, o coeficiente revela $\mathrm{Cll}$ em períodos esparsos e reduzidos, de modo que o comércio se caracteriza como predominantemente interindustrial para tais setores do estado. 
PADRÃO DE ESPECIALIZAÇÃO DO COMÉRCIO INTERNACIONAL DO MARANHÃO (1999-2016)

Tabela 4 - Índice de comércio intraindústria individual para o Maranhão

\begin{tabular}{|c|c|c|c|c|c|c|c|c|c|c|c|c|c|c|c|c|c|c|}
\hline Grupos de Produtos\Ano & 1999 & 2000 & 2001 & 2002 & 2003 & 2004 & 2005 & 2006 & 2007 & 2008 & 2009 & 2010 & 2011 & 2012 & 2013 & 2014 & 2015 & 2016 \\
\hline Alimentos/fumo/bebidas & 0,33 & 0,33 & 0,30 & 0,31 & 0,23 & 0,18 & 0,13 & 0,14 & 0,18 & 0,17 & 0,23 & 0,36 & 0,34 & 0,23 & 0,39 & 0,40 & 0,32 & 0,91 \\
\hline Químicos & 0,68 & 0,61 & 0,81 & 0,72 & 0,80 & 0,87 & 0,84 & 0,83 & 0,97 & 0,68 & 0,79 & 0,67 & 0,67 & 0,80 & 0,69 & 0,60 & 0,57 & 0,52 \\
\hline Calçados/couro & 0,22 & 0,30 & 0,53 & 0,08 & 0,14 & 0,01 & 0,00 & 0,02 & 0,00 & 0,05 & 0,99 & 0,20 & 0,09 & 0,33 & 0,32 & 0,23 & 0,35 & 0,18 \\
\hline Madeira & 0,01 & 0,00 & 0,08 & 0,01 & 0,04 & 0,04 & 0,02 & 0,02 & 0,01 & 0,21 & 0,38 & 0,10 & 0,03 & 0,05 & 0,17 & 0,07 & 0,07 & 0,63 \\
\hline Papel & 0,00 & 0,00 & 0,00 & 0,08 & 0,00 & 0,01 & 0,01 & 0,02 & 0,00 & 0,00 & 0,00 & 0,00 & 0,00 & 0,00 & 0,00 & 0,00 & 0,00 & 0,00 \\
\hline Metais comuns & 0,01 & 0,03 & 0,15 & 0,03 & 0,04 & 0,02 & 0,03 & 0,04 & 0,04 & 0,06 & 0,21 & 0,27 & 0,17 & 0,16 & 0,35 & 0,22 & 0,50 & 0,36 \\
\hline Máquinas/equipamentos & 0,00 & 0,00 & 0,00 & 0,00 & 0,00 & 0,00 & 0,00 & 0,00 & 0,00 & 0,01 & 0,01 & 0,00 & 0,00 & 0,00 & 0,00 & 0,00 & 0,00 & 0,01 \\
\hline Material transporte & 0,00 & 0,00 & 0,02 & 0,01 & 0,02 & 0,00 & 0,00 & 0,00 & 0,00 & 0,00 & 0,00 & 0,00 & 0,00 & 0,00 & 0,00 & 0,00 & 0,00 & 0,02 \\
\hline Ótica/instrumentos & 0,00 & 0,00 & 0,00 & 0,00 & 0,00 & 0,00 & 0,00 & 0,01 & 0,00 & 0,01 & 0,00 & 0,00 & 0,00 & 0,00 & 0,00 & 0,00 & 0,00 & 0,00 \\
\hline Outros & 0,66 & 0,02 & 0,16 & 0,09 & 0,07 & 0,00 & 0,01 & 0,18 & 0,07 & 0,99 & 0,00 & 0,00 & 0,76 & 0,74 & 0,91 & 0,01 & 0,29 & 0,00 \\
\hline
\end{tabular}

Fonte: Elaboração própria a partir dos dados MDIC/SECEX (2017b) 
Fazendo a análise do Cll de maneira agregada para os setores, os resultados indicaram comércio interindústria para o Maranhão, variando em torno de 24\% entre 1999 e 2016. Ou seja, em média, o Maranhão apresenta especialização no setor de químicos (o qual também apresentou vantagens comparativas) conforme a Tabela 5.

Tabela 5 - Índice de comércio intraindústria - Cll agregado para o Maranhão

\begin{tabular}{cccc}
\hline Ano & CII & Ano & CII \\
\hline 1999 & 0,09 & 2008 & 0,27 \\
2000 & 0,09 & 2009 & 0,21 \\
2001 & 0,13 & 2010 & 0,56 \\
2002 & 0,08 & 2011 & 0,31 \\
2003 & 0,19 & 2012 & 0,24 \\
2004 & 0,34 & 2013 & 0,17 \\
2005 & 0,35 & 2014 & 0,14 \\
2006 & 0,24 & 2015 & 0,21 \\
2007 & 0,29 & 2016 & 0,35 \\
\hline
\end{tabular}

Fonte: Elaboração própria a partir dos dados MDIC/SECEX (2017b).

Assim, como ressaltado através do cálculo do IVCS, no ClI, o setor químico também foi de destaque competitivo para o estado do Maranhão. De acordo com Oliveira, Pereira e Nascimento (2018), a economia maranhense, por meio de uma presença forte do estado, vem promovendo incentivos fiscais e infraestrutura para a implementação industrial. Assim, a explicação para as exportações do setor químico podem estar relacionadas, em parte, pela implementação da Suzano Papel e Celulose em Imperatriz, implementação que se valeu de toda uma estrutura montada desde a década de 1980, a partir de um projeto de modernização da Amazônia. Os autores, criticando esta modernização promovida pelo estado, apontam que partes das grandes transformações no espaço maranhense são, assim, seletivas, técnicas, acumulativas e essencialmente voltadas para a concorrência das grandes unidades fabris que convocam os elementos espaciais, sobretudo de regiões periféricas, para atender às suas necessidades.

Ainda, a importância do setor químico maranhense está associada à produção e exportação de derivados de alumínio. De acordo com Pereira e Coronel (2015), a economia maranhense, que possuía uma trajetória de longos períodos de tentativa de se industrializar e carecia de grandes investimentos, chegou à década de 1980 com incentivos fiscais oferecidos pelos governos federal e estadual, que trouxeram facilidades de crédito para atrair investidores. Com tais incentivos, um dos principais resultados foi a implantação da Alumar (Consórcio de Alumínio do Maranhão) produtor de alumina e alumínio no estado do Maranhão. 


\section{3 Índice de concentração setorial das exportações - ICS}

A economia maranhense foi comumente pautada nos ciclos da cana-de-açúcar, do algodão e do babaçu. Dos três, o babaçu foi o último que apresentou predominância, entre as décadas de 1920 e 1970. Nas duas últimas décadas do século XX, houve uma predominância da produção intensiva de soja no sul e leste do estado, bem como uma razoável pecuária de corte, ambos entrecortados por segmentos de agricultura familiar. Além disto, o ápice da economia maranhense foi atingido com os enclaves da Alumar e da Vale do Rio Doce, no plano privado, e a Base de Lançamento de Satélites de Alcântara, no plano público. Esse quadro da economia maranhense no final do século XX continuou, sem alterações qualitativas, na primeira década do século XXI. Analisando a economia maranhense de um modo geral, na primeira década do século XXI, cerca de $70 \%$ do seu PIB vêm dos três setores dinâmicos já citados (ferro, alumínio e soja) (PEREIRA FILHO, 2015).

Diante desse quadro, torna-se pertinente verificar o grau de concentração das exportações do estado. A Tabela 6 apresenta o grau de concentração das exportações - ICS do Maranhão.

Tabela 6 - Índice de concentração setorial das exportações para o Maranhão

\begin{tabular}{llll}
\hline Ano & ICS & Ano & ICS \\
\hline 1999 & 0,81 & 2008 & 0,60 \\
2000 & 0,79 & 2009 & 0,59 \\
2001 & 0,75 & 2010 & 0,58 \\
2002 & 0,76 & 2011 & 0,49 \\
2003 & 0,66 & 2012 & 0,48 \\
2004 & 0,61 & 2013 & 0,55 \\
2005 & 0,59 & 2014 & 0,51 \\
2006 & 0,65 & 2015 & 0,52 \\
2007 & 0,64 & 2016 & 0,53 \\
\hline
\end{tabular}

Fonte: Elaboração própria a partir dos dados MDIC/SECEX (2017b)

Como pode ser observado, é possível afirmar que o Maranhão apresenta uma pauta de exportações concentrada em poucos setores, visto que a média do indicador (ICS $=0,62)$ no período analisado oscila entre 0,48 e 0,81, permanecendo acima de 0,50 em 16 dos 18 anos do período. Esse resultado é reflexo das vantagens comparativas do estado, visto que, levados em consideração os resultados alcançados pelo IVCRS, apenas $14,29 \%$ dos setores apresentaram vantagem comparativa, bem como o Cll indica que $92,86 \%$ dos setores apresentam comércio baseado em vantagens comparativas, ou seja, interindustrial. 


\section{PADRÃO DE ESPECIALIZAÇÃO DO COMÉRCIO INTERNACIONAL DO MARANHÃO (1999-2016)}

De acordo com SECEX (2017), ao longo do período, os setores que mais aumentaram as exportações foram papel, minerais, máquinas e equipamentos, material de transporte e têxtil; os setores que apresentaram menor crescimento de exportações foram plástico e borracha, químicos e calçados e couro, e o restante dos setores apresentou decrescimento nas exportações. Em consonância com a Tabela 3 (onde se considera a análise horizontal das exportações), os setores em que mais cresceram as exportações não são aqueles em que o IVCRS indica vantagem comparativa. Entretanto, o setor de químicos apresentou certo crescimento nas suas exportações, o que explica parcialmente o porquê da tendência de concentração das exportações do estado do Maranhão.

\section{CONCLUSÕES}

Este estudo permitiu aprofundar as observações em relação ao padrão do comércio exterior dos diversos setores do estado do Maranhão. A visão integral dos resultados apresentados neste artigo permite destacar as peculiaridades estaduais da competitividade do Maranhão no comércio exterior, mostrando que existem dois grupos competitivos no mercado internacional: metais comuns e químicos. De um modo geral, de acordo com a literatura, o desenvolvimento privilegiado de alguns setores do estado é vinculado à implantação de grandes investimentos estatais, como o complexo Carajás na década de 1980, o qual trouxe consigo vários programas cujos objetivos eram promover a região, como o Programa Grande Carajás, além da implantação da Ferrovia Carajás-Itaqui (e do desenvolvimento de transportes como um todo). Além disto, grandes grupos estão instalados no estado, como é o caso do grupo Celmar e da Suzano Papel e Celulose

Os resultados do IVCRS são oriundos das exportações dos grupos ferro e aço, e corindo e óxidos e hidróxidos de alumínio na forma de ferro fundido bruto não ligado, de alumínio não ligado em forma bruta, da alumina calcinada e ainda, de derivados do setor de celulose. Quanto ao índice de Comércio Intraindústria (CII), os resultados alcançados apontam que tal forma de comércio existe predominantemente apenas para o setor de químicos.

Desse modo, o Índice de Vantagens Comparativas Reveladas Simétricas (IVCRS) e 0 Índice de Comércio Intraindústria (CII) demonstram um padrão de exportação baseado prioritariamente em produtos intensivos em recursos naturais e produtos da indústria de transformação tradicional, os quais são pouco capazes de gerar vantagens comparativas dinâmicas, ou seja, são baseados em inovações tecnológicas, como encontradas nos padrões internacionais de comércio dos países desenvolvidos.

Quanto ao Índice de Concentração Setorial (ICS), o Estado do Maranhão apresenta uma pauta de exportações concentrada em poucos setores, com média do indicador de 0,62 ao longo do 
período analisado, refletindo o IVCRS, visto que apenas os setores de metais comuns e químicos apresentaram vantagens comparativas, sendo estes apenas 2 dos 14 setores da pauta exportadora, e, além disto, o Cll também indica que $92,86 \%$ dos setores apresentam comércio predominantemente baseado em vantagens comparativas, ou seja, interindustrial.

Entre as limitações do trabalho está o fato de os índices utilizados serem estáticos, ou seja, permitem a análise em períodos de tempos específicos, não compreendendo diversas alterações econômicas. Neste sentido, fazem-se pertinentes análises com acuidade, utilizando modelos econométricos, bem como de Equilíbrio Geral Dinâmico de Gerações Sobrepostas, os quais permitem compreender com perspicácia os efeitos das políticas públicas, bem como das barreiras econômicas que os principais importadores colocam.

\section{REFERÊNCIAS}

ANÁLISE DAS INFORMAÇÕES DE COMÉRCIO EXTERIOR - ALICEWEB. Consultas. Disponível em: http://aliceweb.mdic.gov.br/ . Acesso em: 15 jan. 2017.

COUTINHO, E. S.; PEIXOTO, F. V. L.; RIBEIRO FILHO, P. Z.; AMARAL, H. F. De Smith a Porter: um ensaio sobre as teorias de comércio exterior. Revista de Gestão USP, São Paulo, v. 12, n. 4, p. 101 113, out./dez. 2005.

\section{ESCRITÓRIO TÉCNICO DE ESTUDOS ECONÔMICOS DO NORDESTE - ETENE. Diário}

Econômico 2017. Ano - № 195. Exportações do Nordeste aumentaram no primeiro quadrimestre de 2017. Disponível em:

https://www.bnb.gov.br/documents/1342439/1603204/195_17_05_2017.pdf/e316a3a6-f436-38c5-f1a2cd52429f575c . Acesso em: 25 jul. 2017.

FEISTEL, P. R. Modelo Gravitacional: um teste para economia do Rio Grande do Sul. Revista de Economia e Administração, v. 1, p. 94-107. 2008.

GRUBEL, H.; LLOYD, P. Intra-Industry Trade: the theory and the measurement of international trade in differentiated products. London: Macmillan, 1975.

HIDALGO, A. B. Especialização e competitividade do Nordeste brasileiro no mercado internacional. Revista Econômica do Nordeste, Fortaleza: BNE, v. 29, p. 491 - 414, jul./set. 1998.

HIDALGO, A. B.; MATA, D. F. P. G. Competitividade e vantagens comparativas do Nordeste Brasileiro e do Estado de Pernambuco no comércio internacional. In: Anais do Fórum BNB de Desenvolvimento, 2004.

INSTITUTO BRASILEIRO DE GEOGRAFIA E ESTATÍSTICAS (IBGE). Perfil dos Estados. Disponível em: http://www.ibge.gov.br/estadosat/perfil.php?sigla=ma. Acesso em: 19 jul. 2017.

INSTITUTO MARANHENSE DE ESTUDOS SOCIOECONÔMICOS E CARTOGRÁFICOS - IMESC. Boletim de Conjuntura Econômica Maranhense, v. 5, n.2, abr./jun. - São Luís: IMESC, 2017. 
MAIA, S. F. Transformações na estrutura produtiva do estado do Paraná na década de 90: análise por vantagem comparativa. In: MAIA, S. F.; MEDEIROS, N. H. (org.). Transformações Recentes da Economia Paranaense. Recife: Editora Universitária, v. 1, p. 65-88, 2005.

MESQUITA, B. A. de. Notas sobre a dinâmica econômica recente em área periférica: as mudanças na estrutura produtiva do Maranhão. In: CIRCUITO DE DEBATES ACADÊMICOS, 1, 2011, Brasília.

Anais... Brasília: Instituto de Pesquisa Econômica Aplicada (IPEA), 2011.

MINISTÉRIO DO DESENVOLVIMENTO, INDÚSTRIA E COMÉRCIO EXTERIOR. Balança Comercial. 2017a. Disponível em: http://www.mdic.gov.br/comercio-exterior/estatisticas-de-comercioexterior/balanca-comercial-brasileira-unidades-da-federacao. Acesso em 8: fev. 2017.

MINISTÉRIO DO DESENVOLVIMENTO, INDÚSTRIA E COMÉRCIO EXTERIOR. Séries Históricas. 2017b Disponivel em: http://www.mdic.gov.br/comercio-exterior/estatisticas-de-comercio-exterior/serieshistoricas. Acesso em: 8 fev. 2017.

OLIVEIRA, A. B.; PEREIRA, J. M.; NASCIMENTO, A. A. Cadeia produtiva de papel e celulose e transformações recentes no sudoeste maranhense. Revista de Geografia e Interdisciplinaridade, v. 4, n. 12, 2018.

OLIVEIRA, J. B. de; OLIVEIRA, A. B. Reestruturação Produtiva e localização industrial: considerações sobre as estratégias de implantação da Suzano Papel e Celulose em Imperatriz - MA. 2017. Trabalho de Conclusão de Curso (Graduação em Geografia) - Universidade Estadual da Região Tocantina do Maranhão, Imperatriz, 2017

PEREIRA, M. R. da S. Evolução da indústria maranhense nos anos 2000. 2014. 64 p. Dissertação (Mestrado) - Programa de Pós-Graduação em Administração, Universidade Federal de Santa Maria, Santa Maria, 2014.

PEREIRA, M. R. da S.; CORONEL, D. A. O desempenho da indústria maranhense nos anos 2000: uma abordagem a partir da intensidade tecnológica de seu comércio exterior. Revista Econômica do Nordeste, v. 46, n. 2, 2015.

PEREIRA FILHO, J. F. Formação econômica do maranhão: superexploração e estado oligárquico como entraves ao desenvolvimento. In: JORNADA INTERNACIONAL POLÍTICAS PÚBLICAS, 7, 2015, São Luís. Anais... São Luís: Universidade Federal do Maranhão, 2015.

RICARDO, D. Princípios de economia política e tributação. São Paulo: Abril Cultural, 1982.

ROSSI JÚNIOR, J. L.; FERREIRA, P. C. Evolução da produtividade industrial brasileira e abertura comercial. Pesquisa e Planejamento Econômico, Rio de Janeiro, v. 29, n. 1, p. 1-36, abril 1999.

SANTOS, P. R. dos. Intensidade tecnológica, especialização comercial e competitividade: uma análise da indústria de transformação do Nordeste. 2011. 126 f. Dissertação (Mestrado) Programa de Pós-Graduação em Economia, Universidade Federal de Alagoas, Maceió, 2011.

SILVA, A. R. da. Comércio exterior e desenvolvimento econômico do Maranhão na primeira década do século XXI: uma análise sob a ótica da competitividade revelada. 2013. 116f. Dissertação (Mestrado em Desenvolvimento Socioeconômico) - Universidade Federal do Maranhão, São Luís, 2013. 
SILVA, M. L. da; SILVA, R. A. da; CORONEL, D. A. Padrão de especialização das exportações do Espírito Santo (1999-2014). Revista Brasileira de Estudos Regionais e Urbanos (RBERU), v. 9, n. 1, 2015.

SILVA, M. L. da; SILVA, R. A. da; CORONEL, D. A. Padrão de especialização do comércio internacional de Minas Gerais (1999-2014). Revista competitividade e sustentabilidade - ComSus, Paraná, v. 3, n. 2, 2016.

SILVA, R. A. da; CORONEL, D. A.; SILVA, M. L. da; VIEIRA, V. C. Padrão de especialização das exportações do Brasil (1999-2014). Revista Espacios, v. 38, n. 17, 2017.

SMITH, A. A riqueza das nações. Rio de Janeiro: Hemus, 1984.

Notas

1 Este artigo é oriundo de um projeto de pesquisa financiado pelo CNPq, o qual visa analisar o padrão de especialização de todos os estados da federação.

2 O Sistema Aliceweb2 está disponível no site http://aliceweb2.mdic.gov.br (ALICEWEB, 2017).

3 Embora o produto "celulose" possa ser facilmente associado ao setor de "Papel", vários subprodutos de origem vegetal, resultados de processos químicos da indústria de transformação, são classificados como pertencentes ao setor de "Químicos". 